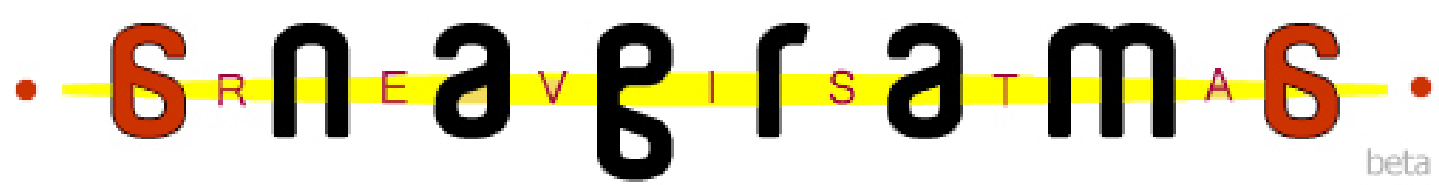

\section{Estratégias de manutenção de Turno}

\author{
Gisele Uieira da Silua ${ }^{1}$
}

Gisleide Alues Anhesim Portes

Lisliere Dantas da Conceição

\section{Resumo}

O objetivo deste artigo é avaliar, seguindo o modelo de Análise da Conversação, a entrevista com um falante culto da cidade de São Paulo e explorar as estratégias de manutenção de turno.

Palauras-chaue: turno, manutenção, marcadores conversacionais

\section{Introdução:}

O presente artigo tem como corpus a gravação de uma entrevista informal caracterizada como DID, ou seja, diálogo entre Interlocutor e Documentador (es). Consiste na análise de um recorte de trinta minutos da gravação, cujo objetivo é examinar o modo pelo qual o informante mantém o seu turno. Participam o professor GC, como entrevistado, e as autoras desse artigo, alunas do $1^{\circ}$ ano de graduação de Letras, como entrevistadoras.

A intenção era a de obter um diálogo espontâneo entre L1 e L2. No entanto, dadas as circunstâncias, L1 assumiu a posição de condutor da conversação já de início, de forma a "ocupar a cena", segundo Galembeck (2003), por meio da inserção de tópicos sobre os quais desenvolveu-se a entrevista.

Por essa razão, optamos por analisar as estratégias por ele usadas que impossibilitaram a tomada de turno por quaisquer das interlocutoras.

Nosso informante é professor aposentado da USP há pouco tempo, cerca de seis meses, tem 71 anos de idade, é natural da cidade de São Paulo e reside atualmente com seu único filho. Aprecia tanto as letras, quanto o jazz e a fotografia. Possui ainda página pessoal na internet.

\footnotetext{
${ }^{1}$ Alunas de Letras da Faculdade de Filosofia, Letras e Ciências Humanas da Universidade de São Paulo.
} 
As entrevistadoras são: LDC, estudante do primeiro ano de Letras,solteira, 20 anos de idade. Natural de Uauá, Estado da Bahia, reside atualmente em São Paulo; GAAP, estudante do primeiro ano de Letras, advogada, casada, 32 anos de idade. Natural de Assis, Estado de São Paulo, reside atualmente em São Paulo; e GVS, estudante do primeiro ano de Letras, solteira, 24 anos de idade.Natural de Taquaritinga, Estado de São Paulo, reside atualmente na cidade de São Paulo.

\section{Caracterização do discurso: Simetria e Assimetria}

A conversação tem como uma das principais características a alternância de turno entre os interlocutores, no caso o falante e o ouvinte. Essa alternância de turnos permite perceber uma organização no texto conversacional.

$\mathrm{Na}$ organização do texto conversacional em questão, podemos perceber claramente que a entrevista com nosso interlocutor se trata de uma conversa simétrica. $O$ termo simetria diz respeito a uma conversação onde um dos interlocutores 'ocupa a cena', por meio de uma série de intervenções de nítido caráter referencial, ou seja, de intervenções nas quais se desenvolve o tópico ou o assunto do fragmento. O outro participante só contribui com intervenções episódicas, secundárias em relação ao tópico do fragmento conversacional”. Em contraposição, na organização do texto conversacional, temos uma conversa de tipo simétrica, na qual "ambos os interlocutores contribuem efetivamente para o desenvolvimento do tópico conversacional". Tudo conforme ensina Marcuschi (2003).

Sendo assim, em nossa entrevista é nítida a situação assimétrica que se desenvolve ao longo do discurso, pois temos a exposição de um único ponto de vista, no caso de L1, e não há discussões envolvendo os outros interlocutores a respeito do tópico inicialmente inserido.

É o que se pode verificar nos trechos da transcrição das linhas 244 a 275, onde L1 domina a conversação por um significativo intervalo de tempo. Após esse longo trecho a única intervenção de uma das interlocutoras se dá na linha 269 , onde L3 se insere no discurso com o recurso não verbal "ahã”. Vejamos:

L1

lá ia eu... ((risos)) né... lá até eu tinha três crianças... tinha o inglês tinha lingüística que eu dava às vezes... lá na universidade não é grande um professor de lingüística dava conta de TUdo... mas se ele ia pra um congresso eu dizia "Geraldo dá uma aula de um tal assunto pros meus alunos..." lá ia eu né... e lá eu ganhei um presente que me deu muito trabalho no começo mas fo::i dá um curso de metodologia da pesquisa / pesquisa não especificamente área (de lingüística)... que era um curso muito interessante como proGRAma... e me fez estudar muito também mas quem mais ganhou com isso fui eu... não foram os alunos 
((risos)) né... eu adorava o curso e pegava uns alunos muito interessantes né aqueles alunos do programa Pet... né quer dizer um pessoal muito interessado que queria fazer porque:: queria aprenDER... não era só por crédito... e tinha éh era um curso que era dado no fim da graduação pra alunos de quinto ano da graduação ou primeiro da pós então eu tinha muitos alunos da pós e era interessante... esse pessoal todo era um curso que eu adorava... e adorei principalmente porque eu aprendi horrores né... nesse curso ((risos))... ma::is... quando eu me aposentei lá.... foi naquela época que:: o Collor falou em mudar a aposentadoria né... e todo mundo se aposentou ((risos))... foi até irônico porque na época até o reitor da universidade se aposentou ((risos)) / não ele ficou até o fim do mandato... como reitor ele ficou até o fim do mandato depois saiu... então o pessoal brincava "o último que sair apaga a luz"... né ((risos))... e:: eu não apaguei a luz porque não fui o último que saiu mas eu me aposentei eu tinha mais de trinta anos de serviço... tudo o que eu tinha feito contava.... né e eu me aposentei e NEssa época conversando com uma amiga aqui da Usp que hoje é aposentada também... ela me disse que ia ter um concurso aqui... "porque que você não faz?"... não / não é questão de fazer coisa diferente... eu não tava pensando de dar aula... eu vinha cheio de / de outros planos.... e ela muito sábia... ela disse "faz esse concurso cê tá voltando pra São Paulo... um salário a mais não vai te prejudicar" e era legal eu nem sabia disso na época que eu fiquei sabendo que eu podia fazer concurso e entrar em outra oficial

bom senso... né eu vim fiz o concurso e passei e comecei e gostei e fiquei... e as outras coisas que eu pensava em fazer eu não fiz nenhuma delas ((risos))... / não mas... eu não me espanto com isso porque a vida inteira é assim né você planeja uma coisa faz outra você diz eu nunca vou ser professor na minha vida eu completei cinqüenta Anos... né eu ia ser médico nunca fui...

\section{Turno}

A idéia de turno está ligada às várias situações em que os membros de um grupo se alternam ou se sucedem na consecução de um objetivo comum: jogo de xadrez, corrida de revezamento, mesa-redonda, de acordo com Preti (2003). Assim, na análise da conversação, podemos entender turno como aquilo que um falante faz ou diz enquanto tem a palavra, incluindo também a possibilidade de silêncio. O turno se trata de qualquer intervenção do interlocutor.

\subsection{Caracterização dos tipos de turno}

Dentro da caracterização de turno temos os denominados turnos nucleares e os turnos inseridos. O primeiro veicula informações, de modo que o falante desenvolve o tópico em andamento. Já o turno inserido não transmite conteúdos informativos e sim a indicação de que o interlocutor está atento ao falante.

No seguinte trecho, que se refere às linhas 21 a 29, perceberemos que L1 tem a posse do turno nuclear, pois desenvolve o tópico "trabalho na USP", ao passo que L2 apenas intervém com breves elementos como "que legal" e "ah::tá", que são os turnos 
inseridos. L2 insere esses elementos no discurso com o intuito de demonstrar a L1 sua atenção.

L1 a minha carreira aqui na universidade é:: relativamente curta.. pelo seguinte... eh.. eu já havia trabalhado na Usp antes em mil novecentos e sessenta e seis eu fui professor na Usp da Maria Antonia na cadeira de língua inglesa.... depois eu saí.. não briguei com a universidade eu tinha uma coisa interessante... eu preferi.. aceitar um emprego numa universidade boa dos Estados Unidos

L2

L1 [ $\quad$ e... depois quando eu vim pra cá.... uhn se for contar pela data oficial de contrato assinado foi em noventa e dois.... né / então eu já vim pra cá aposentado por outra universidade

L2

ah:: tá

É interessante ainda notar os outros elementos que L2, por exemplo, dirige à L1 para indicar atenção ou concordância: "uhn uhn”, "ahã", "uhn”, "ah:: tá", "no::ssa", "eh" "a:::h::.". Esses turnos são de valor interacional e também podem se caracterizar como tentativas frustradas de tomada de turno.

\subsection{Turno: tomada e manutenção}

Como dito anteriormente, o texto conversacional em questão tem estrutura assimétrica, já que L1 detém os turnos de fala por um tempo mais longo que os outros interlocutores e, além disso, em muitas partes esses apenas lançam mão dos marcadores conversacionais (fáticos) para concordar com L1.

Geralmente, em análise da conversação, o elemento discursivo "né" é entendido como um marcador utilizado pelo interlocutor como "forma de verificação", ou seja, ele usa esse elemento para confirmar a atenção que seu interlocutor está dispensando em seu discurso e também como uma forma de passar o turno para seu interlocutor.

Contudo, no texto em questão, é possível perceber que o elemento "né" não é utilizado para "verificação". Ao pronunciar esse elemento L1 não ratifica nenhuma das interlocutoras e, não ratificando, evita a passagem do turno. Sendo assim, quando L1 usa o marcador "né", ele não está querendo passar o turno, mas somente mantê-lo.

Vejamos o seguinte exemplo (linhas 40 a 44):

L1 não eu não gostei da idéia sinceramente gostei num sentido.. eu não tenho mais pilhas de duzentas provas pra corrigir ((risos)) né... mas eu sempre gostei de dar aula... né então.. no começo / ço 
acostumar um pouquinho que não tinha que dar aula né ((riso))... ma::is.... o que que eu vou te dizer? você quer sa / vocês querem saber só do meu tempo aqui da Usp?

Nessa passagem, de fato percebemos que L1 utiliza o elemento "né" para "puxar" a atenção dos interlocutores. Contudo, após usar o elemento "né", lança mão dos elementos "mas" e " então", os quais são elementos utilizados por L1 para manter o turno e não passá-lo às suas interlocutoras.

Ao longo das conversação, L1 utiliza o elemento "ma::is" também para manter o seu turno. A saber linha 42: “no começo/ ço acostumar um pouquinho que não tinha que dar aula né ((risos))... ma::is.... o que que eu vou te dizer? você quer sa / vocês querem saber só do meu tempo aqui da Usp?"

Nesse exemplo, verificamos que o elemento "ma::is" é usado para manter seu turno enquanto formula um outro tópico, o que ainda será "encaixado" no mesmo turno, sem passá-lo à outra interlocutora.

O elemento em questão é utilizado diversas vezes ao longo das falas de L1, geralmente com o mesmo objetivo, isto é, manter seu turno e reformular a informação que virá a seguir.

Vejamos ainda alguns exemplos que confirmam que o uso do elemento "ma::is", nesta análise, é bastante significativo, pois é um dos recursos mais utilizados por L1 para manutenção do turno:

Linha 123: "sei a ordem exata das coisas.. não lembro mais das datas.. ma:::is.. nessa preparação para professor de inglês e etc eu fui conhecer lingüística estruturalista americana...”

Linha 227: “eu ia fazer o semestre passado não pude:: ma::is... é uma delícia porque::: tem uma morfologia lin::da.. né com oito gêneros..."

Linha 250 a 257: "eu adorava o curso e pegava uns alunos muito interessantes né aqueles alunos do programa Pet... né quer dizer um pessoal muito interessado que queria fazer porque:: queria aprenDER... não era só por crédito... e tinha éh era um curso que era dado no fim da graduação pra alunos de quinto ano da graduação ou primeiro da pós então eu tinha muitos alunos da pós e era interessante... esse pessoal todo era um curso que eu adorava... e adorei principalmente porque eu aprendi horrores né... nesse curso ((risos))... ma::is... quando eu me aposentei lá... foi naquela época que:: o Collor falou em mudar a aposentadoria né...” 
Nesse caso, L1 muda do tópico "alunos interessados no curso de metodologia e pesquisa" para o "aposentadoria", porém sem passar o seu turno.

Em suma, podemos afirmar que L1 utiliza os marcadores conversacionais "ma::is", "né" e "então" para preenchimento de "brechas" com o intuito de preservação do turno.0

Nas linhas de 174 a 183 é possível perceber que L2 tenta assaltar o turno, entretanto L1 o retoma justamente com o elemento " $m a:: i s "$ :

L1 ai filha... olha... anos sessenta é o máximo que eu sei te dizer ((risos)) porque quando eu trabalhei no Yázigi foi nos anos sessenta... depois saí em sessenta um... né.. mais detalhe é difícil...

L2

mas

L1

ma::is.. eu continuei tocando as duas coisas trabalhando com lingüística o Yázigi na época anos sessenta ainda criou um centro de lingüística aplicada.. foi o primeiro no Brasil eu suponho na América do Sul num tenho certeza... a::hn... isso foi interessante porque projetou muito a escola no mundo inteiro por causa da atividade lingüística como eu já disse pra muita gente eu tinha um ambiente como se tivesse numa universidade... não estava

Nas linhas 71 a 77 percebemos esse mesmo fato. Neste caso, L1 retoma o seu turno com o elemento "então", mesmo com a tentativa de assalto ao turno realizada por L2:

L1 “a faculdade paulista de medicina naquele tempo que não tinha tanto cartaz.. na época.. a Usp era coisa assim oitenta vagas dois mil e tantos candidatos.... e a / e a penerada era violenta... vocês pegaram o tempo que o / o vestibular só reprova se a pessoa tiver o resultado final baixíssimo.. naquele tempo cada matéria era eliminatória...

L2

no:::

L1

(então)... na / na medicina você ia fazia o exame de física.. aquilo enchia prédios lá em

Pinheiros"

No próximo exemplo, que comporta as linhas 93 a 95, L1 retoma seu turno por meio do elemento "né":

L4

"no::: ((riu))

L1 né...e uns problemas complicados.. ele olhava dizia tal coisa.. ele entrou no primeiro exame parece que fez uma carreira muito bonita na medicina ( )" 
Cabe ressaltar que L1 não ratifica nenhuma das interlocutoras, pois desse modo evita a passagem do turno.

\section{Síntese de outros elementos discursiuos importantes no terto em questão}

Na linha 59 o elemento "ma::s" é utilizado para segurar o turno e permitir L1 formular o que vem a seguir.

L1 "né eu não fui tão radical, ma::s.... pra por em poucas palavras.. quando eu era"

$\mathrm{Na}$ linha 63 temos o elemento discursivo "nã:::o", o qual, diferentemente da gramática tradicional, funciona como uma forma de tomar novamente o turno para si.

Na linha 129 , o elemento " $a:$ :hn" utilizado por L1 pode ser entendido como uma pausa, contudo com essa expressão ele mantém o turno para si e não o passa a nenhum interlocutor, como se estivesse pensando.

L1 "como professor... fui tocando... a::hn.. a gente tinha naquele tempo depois não sei o que"

Já nas linhas 213 e 124 o elemento discursivo "aí.. anh", trata-se de uma forma de L1 retornar ao tópico sobre o qual estava falando, sem passar o turno. O tópico em questão é a "lingüística como novidade no Brasil". Após a expressão "aí.. anh", L1 retorna ao tópico que estava desenvolvendo, a saber, o seu envolvimento com a lingüística e com o inglês. De todo modo, o turno prossegue com ele.

L1

“tava bem informado nessa área...aí...a::nh..eu fui deixando aos poucos o inglês..não deixei de vez..." 
Na linha 239 o elemento " $u:: h n$ " aparece como uma maneira encontrada por L1 para prosseguir com seu turno. Nesse caso, ele estava desenvolvendo o tópico "línguas e suas diversas características". Entretanto, ao inserir a expressão " $u: \cdots: h n$, L1 mantém seu turno e muda de tópico, retornando ao "como se tornou professor".

L1 “e o gênero não tá ligado a isso...em nenhuma língua nem na nossa...u::.hn...agora/então dessa maneira eu vim parar aqui"

$\mathrm{Na}$ linha 304 o elemento discursivo "e:.:." é usado por L1 para que tenha tempo de formular o que virá em seguida, sem perder a posse do turno.

L1

“Estados Unidos... ((risos)) né quer dizer no exterior...” e:.:.: eu poderia ter ficado lá...”

Há a mesma ocorrência na linha 310 , onde o elemento "e::." é usado com a mesma finalidade.

Por fim, nas linhas 341 a 344, L1 usa a expressão "bom ahn:...." para manter o turno que já está em sua posse. Ele desenvolvia o tópico "temperatura" e com a introdução dessa expressão passa ao tópico "conclusão da viagem a Cornell”, tudo em um mesmo turno discursivo.

L1

“ ( ) né aí quando eu cheguei em casa e fiz as continhas era menos vinte e um eu falei caramba por isso que eu tava com frio (( risos)) bom ahn:.... fiquei foi ótimo gostei muito fiz bons amigos tudo ...mas acabei voltando.. e:: anos mais tarde.."

\section{Considerações finais}

No presente trabalho pudemos perceber as estratégias e os mecanismos utilizados por um falante culto para manter seu turno e não passá-lo aos demais interlocutores. Aqui construiu-se uma conversação assimétrica, onde L1 possuía o domínio da fala, em detrimento dos outros interlocutores.

É interessante notar que isso pode ter ocorrido pelo fato de a entrevista ter acontecido na antiga sala de L1, o que pode ter contribuído para deixá-lo mais a vontade para falar e dominar o discurso. Ao passo que as outras interlocutoras, por terem convidado 
L1 para uma entrevista e pelo fato de estarem em condição de visitantes em sua sala, podem ter se sentido "intimidadas" a tentar assaltar com mais ênfase o turno de L1.

Assim, é possível inferir que se a entrevista tivesse ocorrido em local neutro para todos os interlocutores, a conversa pudesse ter sido mais simétrica.

Enfim, por meio da análise da conversação, verificamos na fala de falantes cultos do português elementos marcados para a manutenção de seu turno.

Cumpre acrescentar, por último, um aspecto interessante da fala do informante. Embora não tenha sido o objeto do presente estudo e mereça análise própria, como já o fez Preti (1991), nos parece relevante. Trata-se de um senhor de setenta e um anos de idade, cuja fala é marcada também por longas narrativas. Uma vez reunidos para a entrevista e escolhido o tópico, nosso informante se certifica de nossa atenção e usa todo o tempo para narrar uma história, a história de sua vida. A impossibilidade de assaltar o seu turno, que é mantido por ele com bela maestria, revela essa característica muito típica da fala de pessoas com a mesma faixa etária.

\section{Referências Bibliográficas}

GALEMBECK, Paulo de Tarso. "O turno conversacional”. In PRETI, Dino (org.). Análise de textos orais. São Paulo: Humanitas, 2003.

MARCUSCHI, Luiz Antônio. Análise da conversação. São Paulo: Ática, 2003.

PRETI, Dino. A linguagem dos idosos. São Paulo: Contexto, 1991.

PRETI, Dino (org.). Análise de textos orais. São Paulo: Humanitas, 2003. 